\title{
A Comparison of the English Grammatical Errors of Chinese Undergraduates from China and Malaysia
}

\section{Lin Siew Eng}

Asst. Prof., corresponding author, Faculty of Social Sciences \& Liberal Arts, UCSI University, Malaysia, linsieweng@gmail.com

\section{Chen Luyue}

Faculty of Social Sciences \& Liberal Arts, UCSI University, Malaysia, 619895190@qq.com

\section{Chang Kuan Lim}

PhD, U Smart Learning Centre, Malaysia, alexanderckl@hotmail.com

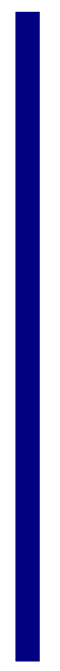

Many of the students of the English Language \& Communication (ELC) department at UCSI University are Malaysian Chinese (MC) students and International Chinese (IC) students from China. All the courses in the university are conducted in English. Currently, there is still lack of research done on grammatical errors among these students who possess the same first language but are from different nationalities. This study aims to investigate the grammatical errors in the IELTS essays written by 16 participants and were analysed using Error Analysis. These participants were divided into two groups namely, the IC students and the MC students to identify the types of grammatical errors made by these participants. The researcher then compared and contrasted the types and frequency of these grammatical errors between the two groups based on the Contrastive Analysis Hypothesis, Creative Construction Hypothesis and Interlanguage Theory. The findings showed that the types of grammatical errors made are mainly errors of omission, misformation, misuse, repetition, vocabulary, structure, coherence/cohesion, expression and misordering. Overall, the results indicated that the IC participants made more grammatical errors compared to the MC participants.

Keywords: contrastive analysis hypothesis, creative construction hypothesis, error analysis, fossilization, interlanguage theory

\section{INTRODUCTION}

English is a global lingua franca, and it is also the most widely learned second language. It is also the preferred language used in most international events. English occupies an

Citation: Lin, S. E., Chen L., \& Chang, K. L. (2020). A Comparison of the English Grammatical Errors of Chinese Undergraduates from China and Malaysia. International Journal of Instruction, 13(1), 931-950. https://doi.org/10.29333/iji.2020.13160a 
important place in the world. It is a compulsory subject in many schools' curriculum and a prerequisite of university application for studying abroad as English is the language for teaching international students (Carvajal, 2007). Having gained the status as the language of global education, many students are now expected to have a fairly good command of the English language.

English is a compulsory subject in Malaysia and China. According to Darus and Subramaniam (2009), English was introduced to Malaya (now Malaysia) during the colonial days and has since then become the second language. In China, English is a foreign language, and it is a requirement in the education system. Every student starts learning English from primary school. Furthermore, English is also a requirement of university application to study abroad. Waghann (2013) reported that the number of Chinese students pursuing higher education overseas has been increasing by about $20 \%$ each year for the past decade. For various reasons, more and more Chinese students are making efforts to learn English.

However, many non-native English learners face many problems especially in writing with correct grammar cited by Alfiyani (2013), being the most crucial aspect of writing. Writing is the most complex skill among the four language skills of listening, speaking, reading, and writing (Darus and Ching, 2009) and Darus and Subramaniam (2009) pointed out that many Malaysian Chinese students are still weak in English, especially in writing as they commit lots of grammatical errors. Meanwhile, Wang and Wang (2012) feel that though writing can show students' comprehensive abilities, unfortunately international Chinese students and teachers pay more attention to acquiring knowledge and neglect the development of the writing ability.

Many researches had identified the problems of grammatical errors in English essay writing by second language or foreign language learners. Ning's (2012) study on Chinese university students, collected and analyzed grammatical errors from essays written in order to provide some suggestions on how to improve the writing ability and its implication in teaching English. There was also a study comparing the written errors of Chinese and Korean university students by Zheng and Park (2013).

Unfortunately, there is still a lack of researches on the grammatical errors among undergraduates. Therefore, this study attempts to discover the differences and similarities in the grammatical errors committed in English essay writing by the International Chinese (IC) students from China and the Malaysian Chinese (MC) students in UCSI University.

Two research questions were formulated to provide insights into the study:

1. What type of grammatical errors are committed by IC and MC participants in English essay writing?

2. What are the similarities and differences of the grammatical errors in English essay writing among the IC and MC participants?

This study is significant for a number of reasons. Firstly, this study identifies the common grammatical errors committed by English as Foreign Language (EFL) learners and English as Second Language (ESL) learners who share the same first language. 
Secondly, this study compares the grammatical errors in English essay writing among the IC and MC participants. Thus, the Chinese students can take note of the common errors and focus on them to improve their writing. Besides, this study also highlights the relationship between the second language learning and the interference of the first language. The findings of this study serve as a reference on the typical grammatical errors made by the IC students from Mainland China and Chinese students from Malaysia.

This study however, has its limitations. The outcomes of the study cannot be used to generalise the language abilities of the IC students and MC students except at the UCSI English language and Communication (ELC) department. The grammatical errors only reflect the written language and not spoken English.

\section{LITERATURE REVIEW}

This study deals with analyzing grammatical errors in English writing. According to Alfiyani (2013), writing is grammatically more complete than speaking as it is able to indicate whether the learners are able to express ideas in the second or foreign language with reasonable coherence and accuracy. However, learners usually make errors when they lack the knowledge of grammar rules, appropriate vocabulary or sentence structures. Errors can reflect the various stages of learning the language. The grammatical errors reflect what is going on in the learners' minds. Therefore, analysing the grammar errors made by learners is very helpful in improving writing besides indicating the possible problems in learning English.

\section{Previous Researches Done on Grammatical Errors in Writing}

Zheng and Park (2013) collected and analyzed writing errors made by Chinese and Korean university students to identify the similarities and differences in their errors with the hope that it could help in the teaching and learning of English in China and Korea. This study makes use of Contrastive Analysis Hypothesis (CAH) and Creative Construction Hypothesis $(\mathrm{CCH})$ as the phenomenon of errors made by participants highlighted by the $\mathrm{CAH}$, is due mainly to participants' preference to translate from their L1. The researchers also felt that the error cluster revealed is also due to the participant's construction of grammar regardless of their L1 background.

Dipolog-Ubanan (2016)'s study investigated the common errors made by Chinese students pursuing the English Language \& Communication programme as well as provide suggestions to address the problems.

This study attempts to identify what aspects of writing in English the Chinese students in UCSI encountered difficulties and suggests some solutions for them. A research conducted by Wang (2011) points out that college students' writing ability has not met the expectations of teaching and the social requirement. There are still many Chinese students who are weak in writing, and the current teaching method is not helping to solve the problem. Chinese students face the problem of interference of L1 in composing sentences adequately. Most of them translate from Chinese into English when constructing sentences. In addition, the cultural thinking mode is another major problem. Chinese students prefer word transformation from L1. 


\section{Error Analysis (EA)}

Every L2 learner will make errors when learning the English language and these errors reveal that there are gaps in learning the language which could be due to various reasons. Corder (1967), noted that the learners' errors are significant because these errors can provide evidence to show how to learn the language, or how language is acquired, and how learners employ whatever procedures or strategies in the discovery of the language. In addition, Brown (2000), believes that error analysis is an important aspect of the study of learners' errors since the learning can be observed, analyzed, and classified to reveal to what extent the learner had learned the language. It is thus reasonable to make use of EA in this study.

There is however a distinction between mistake and error. Mistakes can be selfcorrected since performance errors are caused by carelessness (Alfiyani, 2013). Errors in contrast, refer to competence and cannot be self-corrected (James, 1998). In other words, both native speakers and second language learners make mistakes, but native speakers can recognize and correct mistakes.

\section{Contrastive Analysis Hypothesis (CAH)}

Contrastive analysisHypothesis is used to explain and contrast the similarities and differences between the first language and the target language. Lado, cited in Brown (2000) claimed that the key in making it easy or difficult to learn a foreign language is by comparison of the native and foreign language. CA tries to identify the feature between the first language and the language that learners try to learn, to help learners fit in the new habit intensively. CA is based on the premise that learning a language is learning a set of habits and consequently considered errors as interference due to the habits that were transferred from the mother tongue to the L2. It is also believed that by making a comparison between the two languages most of the learners' errors could be predicted. However, there are some doubts since Contrastive Analysis Hypothesis cannot figure out accurately learner's error and cannot explain why learners with different language background learning the same target language commit similar errors.

\section{Creative Constructive Hypothesis ( $\mathrm{CCH}$ )}

The Creative Construction Hypothesis was advocated by Dulay and Burt (1982). CCH viewed acquisition as a learner driven process that is guided by an innate mechanisms. Learners make unconscious hypotheses based on the input they get from the environment. $\mathrm{CCH}$ considered second language acquisition (SLA) to be very much like L1 acquisition and that L1 acquisition and SLA are basically the same in terms of how acquisition happens (Saville-Troike 2006). Proponents of CCH believed that L1 transfer is negligible and there is universality in acquisition sequences. However, $\mathrm{CCH}$ was severely criticised for failing to account adequately for the problems encountered in foreign language teaching (Van Patten and Benati, 2010).

\section{Theory of Interlanguage}

This theory was first formulated by Selinker (1972) who refers interlanguage as the 
separateness of a second language learner's system from a system that has a structurally intermediate status between the native and target language. He believes that interlanguage is a kind of "between language", that is the learners' exhibition of first language as becoming more proximate with the language they learn. In other words, interlanguage is the type of language produced by language learners who are in the process of learning a second or foreign language (Richards et al.,1996). Through the process of trial and error and hypothesis testing, the learners labouriously succeeded in establishing closer approximations to the system used by native speakers of the language. The learners' language system is neither that of his mother tongue nor that of the second language but contains elements of both.

Thus, interlanguage can be regarded as a permeable, dynamic and systematic process that develops within the second language learners at the same time exhibiting some features of the first language.

\section{Conceptual Framework}

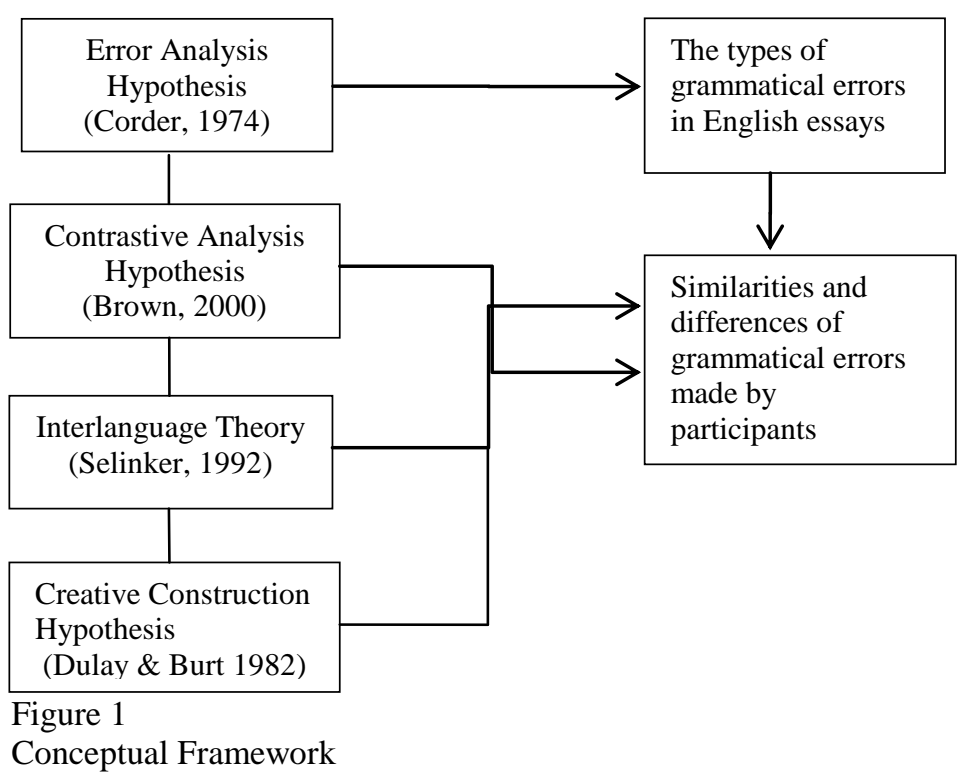

In this conceptual framework, error analysis hypothesis, contrastive analysis hypothesis and interlanguage theory are used to analyse the data. Error analysis is used to analyze the types of grammatical errors made by participants in their writings to address the first research question. Contrastive analysis is commonly used to identify errors due to the negative transfer of the native language to the target language while the Interlanguage theory highlights the phenomenon of language learners' learning progress. These 2 theories address the second research question in analysing the similarities and differences in the grammatical errors as well as find out the causes of the grammatical errors, such as interference of L1, and mother tongue. 


\section{METHOD}

This section will explain the research design, sampling and instrument.

\section{Research Design}

This study uses the mixed method to carry out the research. According to Č́žek (2009), mixed method research is characterized by analysis and data collection based on methodological paradigms. Quantitative data can produce results to access the frequency while qualitative data provides the picture of the situation (Creswell, 2012).

For this study, data was collected for the frequency of the different types of grammatical errors based on the surface strategy taxonomy and the types of grammatical errors identified by an experienced IELTS examiner. The frequency counts and the categories of grammatical errors are analyzed in order to get a detailed understanding of the problems as well as identify the possible causes resulting in these grammatical errors by the IC and MC participants.

\begin{tabular}{|c|c|c|}
\hline $\begin{array}{l}\text { Step } 1 \\
\text { Select participants and } \\
\text { select topic of writing test }\end{array}$ & $\begin{array}{l}\text { Step } 2 \\
\text { Take writing } \\
\text { test }\end{array}$ & $\begin{array}{l}\text { ys to identify the } \\
\text { al errors }\end{array}$ \\
\hline $\begin{array}{l}\text { Step } 6 \\
\text { Compare two groups' writing } \\
\text { performance in terms of } \\
\text { grammatical errors }\end{array}$ & $\begin{array}{l}\text { Step } 5 \\
\text { Describe and explain } \\
\text { grammatical errors in } \\
\text { each essay }\end{array}$ & $\begin{array}{l}\text { Step } 4 \\
\text { Identify the grammatical } \\
\text { errors in each essay and } \\
\text { present in Tables }\end{array}$ \\
\hline $\begin{array}{l}\text { Step } 7 \\
\text { Identify possible factors } \\
\text { which cause grammatical } \\
\text { errors for each group }\end{array}$ & $\begin{array}{l}\text { Step } 8 \\
\text { Make conclusion to } \\
\text { answer research } \\
\text { questions } 1 \text { and } 2\end{array}$ & \\
\hline
\end{tabular}

Figure 2

Research Design

\section{Sampling}

The sampling method used in this study is Devers \& Frankal's (2000) purposive sampling. The researcher selected 16 participants who possessed the same first language (Mandarin) but are of different nationalities. They were put into two groups with 8 students in each group. 8 of them are International Chinese (IC) students from Mainland China while the other 8 are Malaysian Chinese (MC) undergraduates from the Chinese community in Malaysia.

\section{Instrument}

This study uses a writing task as the instrument to collect the data. The participants were required to complete a writing task selected from an IELTS test. Each participant had to write an essay of at least 250 words in 40 minutes. 


\section{FINDINGS}

The data analysis and interpretation of this study are divided into two parts and are described according to the sequence of the research questions. The first section states the findings on the types of grammatical errors made by the IC and MC participants. The second section depicts the similarities and differences between the grammatical errors made by IC and MC participants.

This study reveals that errors are largely caused by the influence of L1, especially L1 interference or L1 transfer errors. The data collected from the interview also revealed participants' tendency to translate from their L1 to English when writing in English.

\section{Research Question 1}

From the data collected, 245 grammatical errors were identified, 145 grammatical errors were committed by IC participants, and 100 grammatical errors were committed by MC participants. According to the comments by the IELTS examiner's, these grammatical errors include omission, misuse, collocation, spelling, punctuation, expression and errors of other categories.

\section{Omission}

According to Dulay, Burt and Krashen (1982), omission error refers to the absence of item that must appear in well-formed structure. In this study, the omission errors are categorized into the omission of the various categories. Table 1 shows the frequency of omission errors for both IC and MC.

Table 1

Frequency of Omission Errors of the Various Categories

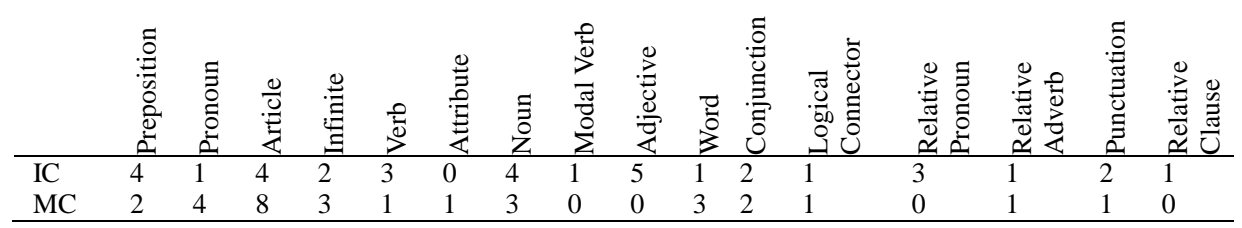

Table 2

Percentage of Omission Errors

\begin{tabular}{ll}
\hline IC & $6.8 \%$ \\
\hline MC & $0.8 \%$ \\
\hline
\end{tabular}

The IC participants made $6.8 \%$ of omission errors whereas the MC participants made $0.8 \%$ of omission errors. Errors of omission of pronoun, preposition and conjunction were the three major grammatical categories mostly committed by the IC participants while the MC participants made omission errors comprising mostly of the pronoun and infinite category. Some examples of omission errors are shown below;

1. [my] teacher also formed a lot of group activities during class time. (Omission of pronoun)-IC

2. Often times we would prefer to go for leisure activities that can help relax the mind 
rather than [those] leisure activities. (Omission of pronoun)-MC

3. But also to prepare their minds for [the] next class. (Omission of article)-IC

4. Be more impressed to the new knowledge and save money [and] time for both teacher and students. (Omission of conjunction)-IC

5. So, children can join [in] some activities. (Omission of infinitive)-IC

6. Next, parents should give chance [to] children to learn other skills such as karate, singing, dancing and more during their leisure time. (Omission of infinitive)-MC

From Tables 1 and 2, IC participants made numerous omission errors of the major categories. Dulay, Burt and Karshen (1982) point out that even though the article which is a grammatical morpheme is omitted, readers are still able to deduce the meaningful clause. However, it was established that some IC participants can only construct sentences using only content words. Thus, they only focus on the content morpheme and omit the grammatical morpheme in accord with Zheng and Park's (2013) view that Chinese language lacks the use of article. Though articles do exist, the articles refer only to number. In the example, "There is a book", "a" refers to number. Therefore, these differences may influence the IC participants in their expressions of thoughts and writing to a certain extent. Another discrepancy is the omission of conjunction in the Chinese language which may also influence their writing. Ma cited in Zheng and Park (2013) states that the Chinese focus mostly on semantics, and Chinese expressions require fewer conjunctions.

\section{Misuse}

Table 3 shows the percentage of 'misuse' errors by the participants.

Table 3

Percentage of Misuse Errors

\begin{tabular}{ll}
\hline $\mathrm{IC}$ & $14 \%$ \\
\hline $\mathrm{MC}$ & $11 \%$ \\
\hline
\end{tabular}

The IC participants made $14 \%$ of misuse errors and the MC participants made $11 \%$ of misuse errors. Some examples are shown below;

1. Maybe they cannot get any friends after [in] they grow up. (Misuse of preposition)-IC

2. Children should have their own time to have some leisure activities [in] either educational or non-educational (Misuse of preposition) -MC

3. For example, teachers can teach students [the] new words by using pictures or role play. (Misuse of article)-IC

4. Normally, a Malaysian child studies [an] approximately 10 hours per day. (Misuse of article)-MC

5. It could benefit them to have more [competitive ability] than others (Misuse of noun) IC

6. I believe that a non-educational leisure activity can help children learn how to balance their life-style and manage their time on [importance] things and leisure activities. (Misuse of noun)-MC

7. For example, after your mother cook for you [and] you should say thanks to your mother for her dishes which make you feel full. (Misuse of conjunction)-IC 
8. This is [as] it is difficult to determine whether the leisure activity is educational or not. (Misuse of conjunction)-MC

Misuse errors include addition errors and Dulay, Burt, and Karshen (1982), state that addition errors are the opposite of the omission error, that is, the presence of the item which should not appear in a well-formed structure. For example, "Maybe they cannot get any friends after [in] they grow up", the preposition of "in" is the addition.

It was noted that the participants were unclear about the misuse of nouns. Word class is the basic knowledge for English language learners but the participants are still not sure and made errors regarding the misuse of nouns. Selinker (1972), states that the phenomenon of fossilization in learning refers to some non-target language, such as grammar and phonetics which exist in interlanguage is difficult to correct. According to Miller (2005), native speakers can use articles correctly but most English language learners have difficulties with the articles and simply misuse the articles. This problem faced by the IC learners most probably revealed that the learners' inter-language has reached a certain level and will remain at that level without any more progress. Some errors will remain permanently.

It was also found that the adjective category is the most misused class of words by the IC participants between the two groups of participants while the MC participants committed some errors in the misuse of words. Some of the examples are as follow;

1. If children don't join [some] activities, they cannot get experience in the society. (Misuse of adjective) -IC

2. This can help them build a healthy body and also [destress]. (Misuse of word] - MC

It can be seen that participants are not familiar with the use of adjective. For example, for the IC participants, though they have been told that "some" is used in positive sentence while "any" is used in negative sentence and interrogative sentence but this rule does not exist in the Chinese language. It is quite obvious that inspire of the years of learning grammar, fossilization had crept in because their errors were not corrected immediately when they practicing the language (Chang and Park, 2013). Another highly possible explanation could be due to the fact that as FL or an L2 learner, the ICs are constantly in the midst of basically Chinese learners only. This situation limited their exposure to English. In Selinker's (1972) view, this is due to fossilization as a result of language transfer which means that sometimes the rules and subsystems of the interlanguage may be transferred from the first language. Selinker considered language transfer as a very powerful factor leading to fossilization and the IC are greatly influenced by their first language. Consequently, they cannot produce the correct second language output. For MC participants, grammar is not taught explicitly, but their sense of language leads them to avoid making this type of error. According to Darus and Ching (2009), the most common errors made by MC students are mechanics, tense, preposition and subject verb agreement. The MC students however, are able to use adjective adequately. 


\section{Misformation}

Dulay, Burt \& Krashen (1982), refer misformation error to the wrong use of morphology. In this study, misformation errors are classified into misformation of article, misformation of verb, misformation of adverb and misformation of word. Table 4 shows the percentage of misformation errors for both groups of participants.

Table 4

Percentage of Misformation Errors

\begin{tabular}{ll}
\hline $\mathrm{IC}$ & $0.8 \%$ \\
\hline $\mathrm{MC}$ & $1.2 \%$ \\
\hline
\end{tabular}

The misformation errors are different between these two groups. The IC participants made $0.8 \%$ of misformation errors whereas the MC participants made $1.2 \%$ of misformation errors. Some examples are shown below;

1. However, I am standing in [a] opposite side with them. (Misformation of article)-IC Some examples of the errors for the misformation of verb, adverb and word by the MC participants are as follow.

1. The most important thing is, when children [doing] these leisure activities with passion and real interest. (Misformation of verb)-MC

2. Proper exercising and participation in sports are key to ensure that child grows up [healthy]. (Misformation of adverb)-MC

3. This raises the question of whether participation of sports as educational of [uneducational]. (Misformation of word)-MC

The presence of misformation error reveals that the participants are unclear about English morphology. For example, in the misformation of article, the indefinite article of "an" should be before vowels. The IC participants find it difficult to apply the phonetics, so they rely mostly on memorizing the grammar rules in learning English. Mushin's (2016) study reveals that misformation errors usually occur because learners do not understand the grammar rules. Thus, the participants' English competencies become fossilized since they do not understand the grammar rules. It is possible that fossilization is the main cause for the misformation of article.

\section{Repetition errors}

Repetition refers to repeating the same word or content. From Table 5, it is found that IC participants made more repetition errors in writing.

Table 5

Percentage of Repetition Errors

\begin{tabular}{ll}
\hline IC & $2.9 \%$ \\
\hline $\mathrm{MC}$ & $0.4 \%$ \\
\hline
\end{tabular}

The following are some examples;

1. In my opinion, [I think] children should just enjoy their activities without any stress. (Repetition of expression)-IC

2. Parents should [be more] take more responsibility on children's growth by 
supervising their leisure's activities. (Repetition of expression)-MC

3. To conclude, my point is that having leisure activities should not [must] be educational. (Repetition of model verb] -IC

4. I['m] agree. (Repetition of verb) -IC

5. There are two points for why it is [be] necessary. (Repetition of verb) -IC

6. Firstly, children should learn [that] how to thanks people who give them hand. (Repetition of relative pronoun)

To recap, the IC participants made $2.9 \%$ of repetition errors whereas the MC participants made $0.4 \%$ of errors. This type of error indicates two problems in learning English. When the participants repeated the same content in a clause, it showed that the participants do not understand the organization of clauses. As for the repetition of vocabulary when the participants repeated the same words, such as relative pronoun or verb, it showed that the participants are unsure of the grammar rules and are basically very careless.

\section{Vocabulary errors}

According to Alqahtani (2015), the knowledge of vocabulary is often viewed as an important tool for language learners because the limited vocabulary in the second or foreign language impedes successful communication and writing. Table 6 shows the errors of vocabulary made by IC and MC participants such as; collocation, fixed usage, spelling, tense, plurality and subject-predicate consistency. The following are some examples;

1. The [various] of activities was actually facilitating student's critical thinking. (Collocation)-IC

2. So I insist children's leisure activity should be something that they enjoy the most and it is stress-free for them regardless [ ] whether it is educational or not. (collocation)-MC

3. The second reason why I agree with the statement is that leisure activities can [facilitated] children's critical thinking. (Fixed usage]-IC

4. Such as what [emontions] that students have to fill into the [roe] and how to [performe] the role in right way. (Wrong spelling)-IC

5. As a conclusion, it is [underiable] that leisure activities should [incorpoate] educational elements. (Wrong spelling)-MC

6. For example, when I [was study] in primary school, my teacher always [form] a lot of group activities during class time, such as role enactment. (Tense) -IC

7. During my childhood, we [feel] free to do whatever we [like] in the outdoor and it was encouraged by both of my parents. (Tense)-MC

8. For example, my [pastor] never let his children purposefully learn something as what they learn from school. (Plural) -IC

9. All in all, leisure time can be spent doing things you enjoy while it actually helps in learning many more [skill] that you can't learn in a educational setting. (Plural)-MC 10.It [encourage] children to face facilities in their life. (subject-predicate consistency)IC 
11. Mental health is a very important element that should not be ignored, no matter what age group the person [belong] to. (subject- predicate consistency) $-\mathrm{MC}$

Table 6

Frequency of Vocabulary Errors for the Various Categories

\begin{tabular}{lccccccc}
\hline & Collocation & $\begin{array}{l}\text { Fixed } \\
\text { Usage }\end{array}$ & Spelling & Tense & $\begin{array}{l}\text { Singular } \\
\& \text { Plural }\end{array}$ & $\begin{array}{l}\text { Subject- } \\
\text { predicate } \\
\text { consistency }\end{array}$ & $\begin{array}{l}\text { Percentage } \\
\text { of Vocabulary } \\
\text { Errors }\end{array}$ \\
\hline $\mathrm{IC}$ & 1 & 1 & 3 & 1 & 1 & 7 & $26 \%$ \\
\hline $\mathrm{MC}$ & 1 & 0 & 0 & 0 & 0 & 5 & $23 \%$ \\
\hline
\end{tabular}

Table 6 shows the similarities in the categories of vocabulary errors. The IC participants made $26 \%$ of vocabulary errors whereas the MC participants made $23 \%$ of vocabulary errors. In terms of number of spelling errors, IC participants spelt some vocabularies wrongly in the writing test. The IC participants are weaker in spelling than the MC participants. In the Chinese education system, IC participants learn vocabularies inefficiently. Sinhaneti and Kyaw (2012) state that most foreign language learner use rote learning. They prefer repeating and reading vocabularies loudly to remember how to spell them. However, MC participants made almost the same number of vocabulary errors as the IC participants. They tend to be careless and made simple spelling errors and lack consistency with the use of tense, collocation and subject-predicate.

\section{Sentence errors}

Sentence structure is the arrangement of phrases, words and clauses in a sentence, and the grammatical meaning of the sentence depends on the structure of organization (Nordquist, 2018). The following are some examples of errors of sentence structure and organization;

1. Children's education case takes many people's attention in a current society, [no doubt] that almost every parents care their children's education problem.- [There is no doubt] (sentence structure) -IC

2. Besides, leisure activities [must be educational] will help children know more things compared with peers. -[with educational functions] (sentence organization)-IC

Table 7

Frequency of Errors of Sentence Structure and Sentence Organization

\begin{tabular}{lclc}
\hline & \multicolumn{3}{c}{ Number of Errors } \\
\hline IC & Sentence Structure & Sentence Organization & Percentage of Structure Errors \\
MC & 4 & 3 & $2.9 \%$ \\
\hline
\end{tabular}

Table 7 shows the errors committed in sentence structure and sentence organisation. The IC participants made $2.9 \%$ of errors whereas the MC participants did not make any error. According to Wang and Chen (2013). the Chinese language basically shares the same SVO-structure with the English language with verbs being the cores in English sentences. However, the Chinese language differ in the use of verbs where the verbs are used to present things orderly according to the time when things happened. This difference in syntactic features has an effect and may possibly influence the IC participants to make 
errors in sentence structure and organization.

\section{Errors of coherence/cohesion}

According to Min (n.d.), coherence refers to the connection of ideas at the idea level, cohesion refers to the connection of ideas at the sentence level. While cohesion shows the grammatical aspects of writing, coherence is the "rhetorical" aspects of writing such as developing and supporting your argument. There following are some examples; Thirdly, the educational activities are [ ] an effective way to help children combine games and knowledge. - [also] (Logical coherence)-IC

So, children can join in some activities, improve their brain and understand more things. [For] their development is very well in the future. [ for] (sentence cohesion] -IC

Table 8

Frequency of Coherence/Cohesion Errors

\begin{tabular}{llll}
\hline & Sentence Coherence & Logical Coherence & Percentage of Coherence/Cohesion Errors \\
\hline IC & 1 & 1 & $0.8 \%$ \\
MC & 0 & 0 & $0 \%$ \\
\hline
\end{tabular}

Table 8 shows the number of coherence/cohesion errors committed. The IC participants made $0.8 \%$ of coherence/cohesion errors whereas the MC participants did not make any coherence/cohesion error. Liu \& Qi (2010), state that though Chinese and English are distinctly different in terms of cohesion and coherence, they are associated with the fossilization of transfer of cultural background. The coherence and cohesion errors made by the IC participants are generally caused by the interference of the L1.

\section{Structure errors}

Table 9 shows the frequency and percentage of structure errors, namely; passive structure and parallel structure. The passive structure is "to be + past participle" while the parallel structure is the repetition of chosen grammatical form within a sentence which follows the same grammatical pattern. Some of the examples are as follow;

1. This is because children need to be [socialize] when they are young so that they are able to talk in front of people in the future. [socialized] (passive structure)-MC

2. Although, I do understand some parents hope to brush up a child's creativity like learning an instrument or [take] up different sports which seems educational as well. [taking] (parallel structure)-MC

Table 9

Frequency of Errors for Passive Structure and Parallel Structure

\begin{tabular}{llll}
\hline & Passive Structure & Parallel Structure & Percentage of Structure Errors \\
\hline IC & 0 & 0 & $0 \%$ \\
MC & 6 & 1 & $2.8 \%$ \\
\hline
\end{tabular}

Table 9 shows that the MC participants made a total of $2.8 \%$ of passive structure and parallel structure errors whereas the IC participants did not record any error as they did not write any sentence with passive voice. MC participants are more inclined to write sentences using passive structure resulting in sentences with wrong verb forms and 
according to Wen (2013), it might be due to the word structure of the students' L1 (Mandarin) which caused the errors in constructing English sentences.

\section{Expression errors}

Expression refers to things that people say, write or do to show their feelings, opinions and ideas. In writing, participants often use expressions wrongly and this confuses the readers. Table 10 shows errors of expression such as wrong expression, improper expression, unclear expression and fixed expression. Fixed expression refers to the standard form of expression which takes the specific meaning rather than the expression itself. Some of the examples of wrongly used expressions are as follow;

1. So, I think [there are both is] helpful for children. [they are both] (wrong expression)-IC

2. This is an exchange for children to recognize [the factors] from leisure activities how to thanks the life. (Improper expression)-IC

3. Without a healthy body, [having knowledge] is futile. (Improper expression)-MC

4. Because during the day, we went to school [them tuition] and did homework at home which required a lot of brain energy and all of these activities were educational. [ ] (Unclear expression)-MC

\section{My mother [was let] me [to] join a dancing class. (Fixed expression)-IC]]}

Table 10

Frequency of Expression Errors for the Various Expressions

\begin{tabular}{llllll} 
& Wrong & Improper & Unclear & Fixed & Percentage of Express \\
& Expression & Expression & Expression & Expression & Errors \\
\hline IC & 4 & 3 & 1 & 1 & $3.6 \%$ \\
MC & 0 & 2 & 2 & 0 & $1.6 \%$ \\
\hline
\end{tabular}

In Table 10, the IC participants made more errors of expression (3.6\%) compared to the MC participants (1.6\%). The IC participants lack the understanding on how to express in English, and there are interference by their own Chinese expressions. In China, the teachers speak in Chinese to teach English, and this makes it difficult for the students to comprehend English which results in the students translating it from their L1. According to Wang and Wang (2012), their study state that Chinglish is primarily caused by the syntactic transfer from the Chinese language. The Chinglish influences the IC participants to make improper and wrong expression.

\section{Misordering errors}

Dulay, Burt and Krashen (1982) pointed out that errors of misordering refer to the incorrect placement of a morpheme or group of morphemes in an utterance. Table 11 shows the frequency of misordering errors made by the IC and MC. The following are some of the examples;

1. [The ideas and thoughts when I learnt from dancing class]-I also learnt some ideas and thought from dancing class. (Misordering) -IC 
2. [Claiming that leisure activities without educational elements are a complete waste of time is too harsh.]-It is harsh to claim that leisure activities without educational elements are a complete waste. (Misordering)-MC

Table 11

Frequency of Misordering Errors

\begin{tabular}{lll}
\hline & Misordering Errors & Percentage of Misordering Errors \\
\hline IC & 3 & $1.2 \%$ \\
MC & 2 & $0.8 \%$ \\
\hline
\end{tabular}

Table 11 shows the errors made in misordering by both the IC and MC participants. The IC participants made $1.2 \%$ of errors and the MC participants made $0.8 \%$ of errors. The participants' errors were fossilized by the L1. Zhou cited in Wang and Chen (2013) state that Chinese people consider matters in a predicative order while in the English language, they tend to make use of backward thinking. This is shown in the following 2 sentences.

A. Claiming that leisure activities without educational elements are a complete waste of time is too harsh. The reason is stated first.

B. It is harsh to claim that leisure activities without educational elements are a complete waste. The result or outcome is given first.

\section{Summary of the similarities and differences between the grammatical errors made by IC and MC participants.}

There are two parts in this section. The first part provides the differences of the grammatical errors made by the IC participants and MC participants. The second part presents the similarities of the grammatical errors made by the IC participants and MC participants.

\section{Differences of the grammatical errors between the IC and MC participants.}

Firstly, based on Tables 1 and 2, in terms of the number of omission errors, IC participants showed a higher frequency in omission errors.

Secondly, a higher frequency in misuse errors is exhibited by the IC participants. They committed mainly adjective errors while the MC participants committed largely word errors.

Thirdly, for misformation errors, IC participants had a high frequency in misformation of article, while MC participants made more errors in misformation of verb, adverb and word.

Fourthly, IC participants made more repetition errors whereas the MC participants committed less repetition errors.

Fifthly, the IC participants made more errors of expression than the MC participants. The Chinese expressions affect the use of expressions by the IC participants.

Sixthly, according to Tables 7 to 12 , the major categories of errors made by IC 
participants are different from the MC participants. These include the errors of cohesion/coherence, expression, and sentence structures. It shows that the IC participants were very influenced by the structure and thinking of L1. However, MC participants made errors of passive structure and parallel structure revealing that they lack of knowledge about the passive structure and parallel structure.

\section{Similarities of the grammatical errors between the IC and MC participants.}

The following are some of the similarities in the types of grammatical errors made by the two groups of participants. Firstly, the categories of vocabulary error are similar in both groups. Both groups made many spelling errors. One possible reason is carelessness. The researcher also monitored the time for the writing test. Most of the participants completed the essay in less than 20 minutes. Another possible reason is that the participants lack the knowledge of vocabulary. Secondly, there are similarities in the categories of misordering errors by both groups. The possible cause is the different ways of thinking and the differences in the structures of Chinese and English sentences.

Table 12

Frequency of Each Type of Grammatical Errors

\begin{tabular}{|c|c|c|c|c|c|c|c|c|c|c|}
\hline & 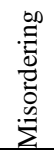 & 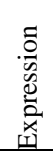 & 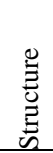 & 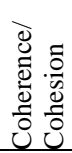 & 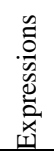 & $\begin{array}{l}\vec{\Xi} \\
\vec{\Xi} \\
\overrightarrow{\tilde{J}} \\
\stackrel{0}{\nu}\end{array}$ & 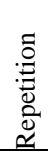 & 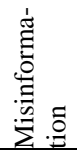 & 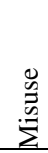 & $\begin{array}{l}\tilde{0} \\
\frac{0}{0} \\
.0 \\
0\end{array}$ \\
\hline IC & 1.2 & 3.6 & 0 & 0.8 & 3.6 & 26 & 2.9 & 0.8 & 14 & 6.8 \\
\hline $\mathrm{MC}$ & 0.8 & 1.6 & 2.8 & 0 & 1.6 & 23 & 0.4 & 1.2 & 11 & 0.8 \\
\hline
\end{tabular}

\section{DISCUSSION}

In general, the differences between mother tongue and the target language are the root cause of mother tongue interference. Every language learner who is learning a second language is likely to experience mother tongue interference. The knowledge of the rules, the linguistic forms and thinking patterns that the learner possessed in his/her native language have an effect on learning the target language. Although mother tongue interference may seem inconsequential it is a significant obstacle in learners' progress toward the target language competence. The interference from mother tongue environment can lead to fossilization. The situation in China is quite different because ICs learn the target language as a foreign language in the mother tongue environment which is very different from the environment of the target language.

The interference of L1 is noticeable as the Chinese language lacks the use of article. Many participants omitted the article "the" in English writing. Similarly, the function of conjunctions in the Chinese language is ambiguous resulting in the participants making errors of conjunctions in English writing.

In addition, according to Kay and Kempton (1984), the way people think is strongly affected by their native language which is in line with the Sapir-Whorf hypothesis. in China, the IC students were taught English by English language teachers of Chinese origin. Ultimately, the command of the language will be influenced and shaped by how 
their language teachers think and speak.

Finally, most participants are easily confused by the word class, such as verb, noun, adjective and adverb. Some of them simply do not understand the grammar rules which is in line with Abdu Mohammed Al-Mekhlafi \& Nagaratnam's (2011) view where they believe that the learners have not learned the rules of grammar even after years of learning. They find difficulty in making use of the rules of grammar and thus end up writing sentences with the wrong structures. It is evident that the students lacked motivation as the learners have been learning the language for some time and had not progressed. Learners who are not interested in the social and cultural customs of native speakers of the language they are learning are more likely to be unsuccessful. In addition, learners who possessed strong instrumental motivation to learn a second language will probably succeed while learners with little interest in the way of life of the native speakers or with low instrumental need tend to learn slowly and to stop learning somewhere. Additionally, once learners have obtained sufficient second language knowledge to meet their communicative or emotional needs, they may drop learning and fossilization may take place. Regardless of how much input or in what form the input is provided, the students are not likely to learn.

\section{RECOMMENDATION}

The teacher should encourage students to be motivated by being enthusiastic, earnest and responsible to create a relaxed and pleasant second language learning environment. In addition, the teacher can help students to develop the right attitudes and not to be afraid of making mistakes as well as enhance their confidence. It would be very motivating if the teacher keep the teaching contents interesting and original. Make learning more interesting by incorporating materials related to the target language such as movies, novels, songs and cartoon. Keeping the learning interesting is a good way to avoid fossilization.

In a culture where teachers and parents attach a lot of importance on examinations there is the likelihood of Hughes' (1989) negative washback effect and teachers then began to spend a lot of time in explaining grammars, syntax and morphology resulting in classroom settings that are teacher-centered rather than learner-centered.

Furthermore, as the participants are laden with the interference of their L1 such as the predicative order of the Chinese language, it would be very helpful if the teachers could create an English environment inside and outside the classroom and make use of student-centred learning to cater to the teaching and learning process. The teachers could direct the learners' attention to the culture and background knowledge of the English-speaking countries as language has a close relation to the culture of the nation and each culture is unique. Therefore, the more one knows about the culture of the target language, the better will he or she be able to understand and appreciate the language. The learners can also learn to understand the differences of his native language and the target language by comparing the differences between the cultures. In this way, they can improve their inter-language brought about by their culture differences. Listening to radio, reading novels, engaging and interacting with native speakers are useful way to 
increase the quality of input. The teachers can also provide learners with interesting media materials that contain culture information and custom of second languagespeaking countries.

It is recommended that English teachers adapt and adjust the teaching methods as there are lots of differences between the Chinese language system and the English language system such as, the lack of the article system and the existence of the different functions of conjunction. Moreover, some participants are confused with the word class. Besides focusing on enhancing the teaching the articles, conjunctions and knowledge of the word class, teachers should provide the right feedback as providing the right feedback is helpful in facilitating second language knowledge construction and enhancing knowledge use. When incorrect language has become a habit, it is very difficult to remove the fossilized errors.

Do not increase the learners' anxiety as this will develop a negative attitude towards the language which may ultimately reduce their interest and confidence. An approach which incorporates the lowering of Krashen's (1982) affective filter such as reducing the stress levels of the activities and tasks in the classrooms would be a constructive change. The affective filter is considered as one of the most important elements that causes individual differences in second language acquisition. Raising the filter would prevent input from passing through and when input is not allowed to pass through, there can be no acquisition

\section{CONCLUSION}

The key findings answered the two research questions which are (1) What type of grammatical errors are committed by IC and MC participants in English essay writing? (2) What are the similarities and differences of the grammatical errors in English essay writing among the IC and MC participants?

For the first research question, it was found that both groups of participants made similar types of grammatical errors. The major types of errors are; omission, misuse, misformation, repetition, structure errors, vocabulary errors, errors of cohesion/coherence, errors of expression, misordering, and sentence errors. This could be due to the fact that the learner's grammar is not perfect. The grammar that the learner had developed is incomplete and unstable. The negative transfer of their mother tongue L1 or overgeneralization of an inter-language rule will lead to some mistakes in learners'application of the foreign language

For the second research question which compares and contrasts the grammatical errors, the IC participants made more grammatical errors than the MC participants except for misformation errors and structure errors. Based on the examples on grammatical errors and the system of their L1, one possible cause of grammatical errors in English writing which the IC participants faced is due to the interference of their L1 which becomes fossilized, besides the limited knowledge of English grammar and vocabulary.

\section{REFERENCES}

Abdu Mohammed Al-Mekhlafi, \& Nagaratnam, P, R. (2011) Difficulties in teaching and 
learning grammar in an EFL context. International J. of Instruction, 4(2), 69-86

Alfiyani, L. M. (2013). An analysis of grammatical errors in writing among the second semester students of English department of Yogyakarta State University in the academic year of 2011/2012 (Unpublished master thesis). Retrieved from http://eprints.uny.ac.id/25706/1/Lulu\%20Meilina\%20Alfiyani\%2006202244055.pdf

Alqahtani, M. (2015). The importance of vocabulary in language learning and how to be taught. International Journal of Teaching and Education, 3(3), 21-34.

Brown, H. D. (2000). Principles of language learning and teaching. San Francisco: Longman.

Carvajal, D. (2007, April 11). English as language of global education. The New York Times. Retrieved from http://www.nytimes.com/2007/04/11/education/11english.html.

Čížek, T. (2009). Review of designing and conducting mixed methods research. Central European Journal of Public Policy, 3(1), 92-95.

Corder, S. P. (1967). The significance of learners' errors. International Review of Applied Linguistics, 5, 161-170.

Corder, S. P. (1974). Error analysis. London: Longman.

Creswell, J. W. (2012). Educational research: Planning, conducting, and evaluating quantitative and qualitative research. Boston: Pearson Education.

Darus, S., \& Ching, K. H. (2009). Common errors in written English essays of form one Chinese students: A case study. European Journal of Social Sciences, 10(2), 242-253.

Darus, S., \& Subramaniam, K. (2009). Error analysis of the written English essays of secondary school students in Malaysia: A case study. Euro. J. of Soc. Sci., 8(3), 483-495.

Devers, K. J., \& Frankel, R. M. (2000), Study design in qualitative research - 2: Sampling a Data Collection Strategies, 13(2), 263-271.

Dipolog-Ubanan, G. F. (2016). L1 Influence on writing in L2 among UCSI Chinese students: A case study. Pertanika J. Soc. Sci. \& Hum,24(4), 1841 - 1853.

Dulay, H., Burt, M., \& Krashen S. (1982). Language two. Oxford: Oxford University.

Hughes, A. (1989) Testing for language teachers. UK: Cambridge University press.

James, C. (1998). Errors in language learning and use: Exploring error analysis. Harlow, UK: Addison Wesley Longman.

Kay, P., \& Kempton, W. (1984). What is the Sapir Whorf hypothesis? American Anthropological Association, 65-79.

Krashen, S. D. (1982). Principles and practice in second language acquisition. Oxford: Pergamon Press.

Liu, L., \& Qi, X. (2010). A contrastive study of textual cohesion and coherence errors in 
Chinese EFL abstract writing in engineering discourse. Interc. Co. Stu., 19(3), 176-187.

Manan, A. A., \& Shamsudin, S. (2012). Comparing form four Malay and Chinese students' spoken English. The English Teacher, 42(1), 13-26.

Miller, J. (2005). Most of ESL students have trouble with articles. Int. E. J., 5(5), 80-88.

Min, Y. (n.d.). ESL: Coherence and cohesion. ESL student handbook of University of Washington. Retrieved from http://www.uwb.edu/wacc/services/eslhandbook/coherence.

Muhsin, M. A. (2016). Analyzing the students' errors in using simple present: A case study at Junior high school in Makassar. Humanities and Social Science, 2, 81-87.

Ning, M. (2012). Implications of interlanguage error analysis and research on English language testing and teaching. Higher Education of Social Science 2(2), 4-7.

Nordquist, R. (2018). What is sentence structure in English? Retrieved from http://www.thoughtco.com/sentence-structure-english-grammar-1691891.

Richards, J. C., Plott, J., \& Platt, H. (1996). Dictionary of language teaching and applied linguistics. London: Longman.

Saville-Troike, M. (2006). Introducing second language acquisition. Cambridge: Cambridge University Press.

Selinker, L. (1972). Interlanguage. IRAL, 10, 209-241.

Selinker, L. (1992). Rediscovering interlanguage. London: Longman.

Sinhaneti, K., \& Kyaw, E. K (2012). A study of the role of rote learning in vocabulary learning strategies of Burmese students. US: David Publishing Company.

Van Patten, B., \& Benati, A. G. (2010). Key terms in second language acquisition. London: Continuum International Publishing Group.

Wahgann, J. (2013). Studying abroad: A prevailing trend for Chinese students. CCTV News. Retrieved from http://english.cntv.cn/program/cultureexpress/20131108/101852.shtml.

Wang, P., \& Wang, W. P. (2012). Causes of and remedies for Chinglish in Chinese college students' writings. Open Journal of Modern Linguistics, 2(2), 71-78.

Wang, Y., \& Chen, J. (2013). Differences of English and Chinese as written languages and strategies in English writing teaching. Theo. and Prac. in Lan. Stu., 3(4), 647-652.

Wen, K. Y. (2013). A study of verb errors in written English by Chinese ESL students (Unpublished master thesis). Retrieved from http://studentsrepo.um.edu.my/5687/1/a_study_of_verb_errors_in_written-english.pdf.

Zheng, C., \& Park, T. J. (2013). An analysis of errors in English writing made by Chinese and Korean University Students. Theory and Practice in Language Studies, $3(8), 1342-1351$. 